\title{
Participatory Design of Healthcare Technology with Children
}

Author: Tara Sims, PhD Health Sciences, MSc Occupational Therapy, BA Hons, Developmental Psychology, Senior Lecturer in Occupational Therapy, School of Health Sciences, University of Brighton, Eastbourne, United Kingdom, Telephone: 01273 643828, e-mail: T.Sims@brighton.ac.uk

Corresponding author: Tara Sims

Corresponding Author's E-mail: T.Sims@brighton.ac.uk

\section{Structured Abstract}

Purpose: There are many frameworks and methods for involving children in design research. Human Computer Interaction (HCI) provides rich methods for involving children when designing technologies.

Design/Methodology/Approach: This article examines various approaches for involving children in design, considering whether users view children as study objects or active participants.

Findings: The BRuger Involvering i Design, GEntænkt (English: User Involvement in Design, Revised - BRIDGE) method is a sociocultural approach to product design that views children as active participants, enabling them to contribute to the design process as competent and resourceful partners. An example is provided, in which the BRIDGE method was successfully applied to developing upper limb prostheses with children.

Originality/value: Approaching design in this way can provide children with opportunities to develop social, academic and design skills and to develop autonomy.

Keywords: Patient centredness; Medical equipment.

Article classification: General review

Received $-4^{\text {th }}$ Nov 2016

Revised -

Accepted -

\section{Introduction}

Recognising children's rights in research has led to a considerable increase in their involvement in research (Morrow and Richards, 1996). Research involving children in healthcare technology design is, however, scant with limited reporting on the methods used and their success. Light et al. (2007) and Rigby et al. (1996) incorporated the views and preferences of children into the design of assistive equipment and Weightman et al. (2010) involved children with cerebral palsy in the development of devices for upper limb therapy. A range of methods to involve children were used, including questionnaires, interviews and peer-tutoring methods. Whilst the researchers found interviews and questionnaires to be useful for gathering the participants' views, they felt that these methods were commensurate with a marginalising power relationship, with the adults being in the position of power when asking the questions. Sims (2014) applied the BRuger Involvering i Design, GEntænkt (English: User Involvement in Design, Revised - BRIDGE) method of participatory design to developing new upper limb prostheses with children, resulting in the production of several prototypes of cost-effective task-specific prosthetic devices. Developing healthcare technology using this method can lead to the creation of products that consider the needs and wants of users as well as technological advancements. 
There are many and varied frameworks and methods for involving children in design research, some view children more as study objects and others as active participants. This raises the question about how to involve children in design in a way that values their opinions and supports their developing autonomy. This article critically discusses some frameworks for involving children in design research, reflecting on child development philosophies and the implications for learning and development. The major participatory design theories that have been implemented in designing children's technology are discussed. Other approaches to technology design with children (user-centred design and contextual design) are not discussed, as the involvement of users in these methods is limited to clarifying researchers' ideas and feeding back shortcomings of products developed (Nesset and Large, 2004). The BRIDGE participatory design method applied to designing healthcare technology with children is also discussed.

\section{Participatory design in child computer interaction (CCI)}

Human computer interaction (HCI) is a considerable advance on other design research fields that involve users in product design, providing rich methods that may be used in involving children in healthcare technology design (Glushko, 2013). Child computer interaction (CCI) is an HCI subfield relating specifically to children's relationships with technology (Markopoulos et al., 2008). The CCI discipline widely accepts that children should be involved in designing new technology for children (Iversen and Brodersen, 2007). Within the CCI discipline, various approaches have been proposed for involving children in design.

\section{Informant design}

The informant design (ID) approach to participatory design with children is based on the premise that participatory design techniques devised for working with adults are not appropriate when working with children. Scaife et al., (1997) suggested that children, as opposed to adults, do not have the expertise or knowledge to participate in a collaborative design process. Informant design was developed as a technique for designing educational technology for children (Scaife et al., 1997). It begins with children and teachers (separately) providing information about their current equipment's strengths and weaknesses, either through observation or discussion-based methods (Scaife et al., 1997). This information is used by designers to identify current problems, which are used to inform functionality specifications. Participating in informant design may be positive for children as it can engender empowerment because their views are sought (Scaife et al., 1997). However, it is evident from Scaife et al's (1997) reasoning behind rejecting established participatory design methods. Informant design is founded on traditional stage-based understandings of children's cognitive development, such as Piaget's (1972) cognitive development theory, which views children as cognitively immature adults (Iversen and Brodersen, 2007).

\section{Cooperative inquiry}

Cooperative inquiry (CI) (Druin, 2002) is another participatory design method that is solely applied to children. It emerged through a growing multidisciplinary interest in children as technology users and producers (Iversen and Brodersen, 2007). It emphasises a multidisciplinary partnership with children and observational research that studies technology's current context (Druin, 2002). Children are paired with designers in 'intergenerational design teams', with the aim that children and designers are viewed as equals in the design process (Druin, 2002). However, the reality is that children may not actually be treated as such. Druin (2002) suggests that children should contribute to the design process in ways that are appropriate to both them and the process, with the decision 
about what is an appropriate contribution likely being made by the (adult) researchers/designers. Furthermore, CI employs observation, not discussion-based methods to inform designers of the child's current situation. Druin (2002) argues that this is necessary as children have difficulty in verbalising their thoughts and opinions and observation provides a concrete experience from which to begin designs. One CI strength is that it recognises that children have different interests and activities to adults. Differences are, however, used to legitimise a dedicated method for technology design with children, which is primarily founded on a Piagetian cognitive development model (Piaget, 1972). This purports that cognitive development occurs in discrete stages throughout childhood in which cognitive skills are acquired and accommodated until the adult cognitive maturity goal is attained (Piaget, 1972). Furthermore, pairing children with adults in design teams could limit and prescribe what children can create as opposed to being entirely open to their views, as qualitative discussion-based methods are able to be (Allsop et al., 2010).

\section{Understanding children's views}

Davis (1998) suggested that the main objective for researchers developing technologies for and with children should be to identify methods that enable children to express their views and opinions fully and actively. Although methods, such as CI, utilise creative and child friendly data collection tools, which aim to increase child participation in research, imply that children cannot hold meaningful conversations in the same way as adults (Kirk, 2007). In bothid and CI, information about design ideas is largely gathered by observing children or through proxy measures, resulting in children being marginal to the process. Informant design and CI are based on traditional psychological child development theories, which argue that children lack adult skills and abilities (James and Prout, 1997). The child is an incomplete adult rather than a complete human being, suggesting that children should be viewed as incompetent and adults as competent (Uprichard, 2008). This perspective implies that competency is something that is acquired as one becomes an adult and that competency is a characteristic that can only be possessed by adults (Uprichard, 2008). This belief that children do not have the competence to contribute to decision-making can result ignoring children's rights to be heard (Lansdown, 2009), leading to adults underestimating children's capacities or failing to consider their views (Lansdown, 2009), which reduces the opportunities children have for developing their capacity for emerging autonomy, which serves to justify their exclusion from decision making, perpetuating the cycle (Lansdown, 2009). Wyness et al., (2004) argued that measuring child status as incompetent against a view of adults as competent, results in an inclination for not adapting research approaches to make them more suitable for children.

\section{A sociocultural approach to children's participation}

Vygotsky (1978) acknowledged Piaget, but voiced the need for a more sociocultural frame for understanding children's development, regarding development as taking place through participation in social practice and being influenced by contextual factors. A sociocultural approach to child development does not assume that children are cognitively less competent than adults (James and Prout, 1997). This approach enables competency to be considered as specific to a situation and social and cultural experiences, rather than as determined by a person's age (James and Prout, 1997). From this perspective, both children and adults can be both competent and incompetent depending on with what they are confronted. Both children and adults are learning and developing competency through their social experiences (Lansdown, 2009). Vygotsky's (1978) child development view provides a theoretical framework that focuses on children's everyday practice (and not their cognitive abilities) as the study object, when studying children and childhood. Children are viewed as actively 
constructing their own childhood, and having views and experiences about being a child (Uprichard, 2008). This shift presents children as agents of their own social worlds and is evident in children's rights legislation. Since the late 1990s, the UK government's policy developments included a commitment to increasing children's involvement in decisionmaking processes about their own care and the services they use (Martin and Franklin, 2009).

\section{A sociocultural approach to designing with children}

A sociocultural approach to product design enables children to participate as competent and resourceful partners with a distinct social view, enabling their decisions to be given equal credence in the design process (Iversen and Brodersen, 2007). A design method that employs this stance is the BRIDGE method (Iversen and Brodersen, 2007). The BRIDGE method is an iterative design process in which children's ideas for product development are sought through conversational methods (Iversen and Brodersen, 2007). Prototypes are then created by a designer and presented to the children for their feedback and elaboration in an ongoing cycle (Iversen and Brodersen, 2007). In the BRIDGE method, children are experts in their everyday lives with their expertise being viewed as equal to any adult and their decisions given equal importance in the design process (Iversen and Brodersen, 2007). The language, materials and environment used should facilitate equal contribution from children and adults through conversational methods that enable children to share their views (Iversen and Brodersen, 2007). The BRIDGE method purports that rather than focussing on cognitive differences implied by arbitrary age categories leading to children being considered as cognitively incomplete, the language, materials and environment should enable equal contribution to the design from children and adults (Iversen and Brodersen, 2007). Applying sociocultural developmental theory to design implies that at the outset, end users (children) understand their current situation. They are, therefore, able to contribute specialist domainspecific knowledge from their own world that to some extent is unknown to the designers. The researcher is responsible for providing the correct techniques and tools for involving children and for understanding the children's viewpoints (as opposed to it being the children's responsibility to make their viewpoint understood) (Iversen and Brodersen, 2007).

\section{Applying to BRIDGE method to healthcare technology - an example from research}

Sims' (2014) research involved the three main stakeholders in children's upper limb prostheses (children, parents and professionals) in developing new prototype devices. The study's overarching aims were to help develop new prosthetic devices for children and young people by exploring stakeholder views. Parents and professionals were involved owing to recognition that different stakeholders are required in healthcare technology development because of differences in training, knowledge and experience, environment, culture, social norms, perceptions and beliefs. However, the process began with involving children in idea generation and device development before involving parents and professionals. This was deemed necessary both for ethical reasons (to respect children's rights to share their views and have their views valued) and to cohere with a sociocultural view of children's participation (by recognising their social worlds as the starting point for design). Table I demonstrates how BRIDGE's key tenets were realised in the Sims (2014) study.

\section{Table I here}

\section{Participatory design - benefits to children}

Guha (2010) reviewed the literature on the benefits to children who take part in participatory design projects and found that participation resulted in social skill development, academic skills acquisition and improvement in general design skills. The social skill development 
found to be influenced by participatory design included an improved ability for children to collaborate, improved communication skills and feelings of empowerment, pride and confidence. Regarding academic skills, design activities were found to result in enhanced content learning (such as about mathematics and information technology) and improved independent learning skills. General design skills developed by children, as identified in Guha's (2010) review, included problem-solving, writing, drawing and creativity. Kafai et al's (2012) study supported these findings, concluding that design activities can provide context for developing creativity and problem-solving skills. Kafai et al., (2012) suggested that children develop increased agency and an understanding about their relationship with the study object through participatory design.

\section{Conversational methods}

Within the BRIDGE method, knowledge about children's everyday lives must be gathered through conversational methods that enable children to share their views. This serves both to respect the child's right to participate and make decisions, and to minimise adult influence on interpreting children's views. A focus group is an appropriate method for enabling children to express their views in research. In focus groups, people are encouraged to talk to one another and comment on the experiences and other group members' viewpoints, enabling the researcher to draw upon participants' opinions, values and experiences, which are more likely to be revealed through social interaction created in a focus group (Kitzinger, 1995). Focus groups are a particularly useful method with children as they minimise the demands that may be placed on children by quantitative methods, such as literacy and reading ability. Kennedy et al. (2001) suggested that children are likely to feel more comfortable with same-age peers and talking with people who have had similar experiences can be a supportive and empowering process (Kitzinger, 1995). Crucially, focus groups acknowledge participants as experts in their experiences, aiming to discover children's world views (Levine and Zimmerman, 1996). This allows the language that is used in the research to remain more relevant to children's social worlds, minimising an adult perspective's influence (Levine and Zimmerman, 1996).

\section{Focus group participation - benefits to children}

Participation in focus groups can benefit children and young people by providing them with the opportunity to be involved in decision making processes and to be valued as experts (Race et al., 1994). Involving children and young people in decision-making can result in enhanced self-esteem and motivation, developing personal, social and organisational skills, and experience with group and democratic processes (Whitty and Wisby, 2007). Furthermore, being given the chance to work collaboratively with researchers can be empowering for children and young people (Goss and Leinbach, 1996). Focus groups can be viewed as social participation through which learning from other community members can occur (Vygotsky, 1978). Providing they are effectively facilitated, focus groups can provide children with opportunities for learning how to: co-operate with each other; respect different viewpoints; express opinions; and evaluate arguments (Vosniadou, 2001). Approaches and techniques can be used to facilitate children's participation in focus groups, such collaboratively setting ground rules, ice-breaker games and activities to help provide a relaxed environment (Lightfoot and Sloper, 2002). Providing art materials, so that children can choose to express themselves in ways other than verbally, if they wish to, can also encourage participation (Turner et al., 1995). 


\section{Children as equal partners}

Respect for children as equal partners in research, as articulated in the BRIDGE method, should also extend to children's decision making about research participation. Informed assent is recommended in research with children and young people as this ensures they have a choice, recognising their developing capacity to make decisions. However, informed assent is required in addition to parental consent, enabling children to remain protected from harm in research. Informed assent is the participant's positive agreement to participate in the study and not merely absent dissent (Broome, 1999). This is particularly relevant as understanding that research participation is voluntary can be difficult for children, as they are socialised to obey adults and look up to them as experts (European Council Working Group, 2008). A thorough approach to assent demonstrates respect for children's privacy by recognising that their right to refuse to participate is equivalent to an adult's rights (McNaughton and Smith, 2005). Additionally, assent should be viewed as an ongoing process to demonstrate respect for children's decisions to voluntarily participate in research (Medical Research Council, 2004). By viewing assent as a continual process, young people are enabled owner their ideas as they can withdraw their data at any stage in the research process (McNaughton and Smith, 2005). Children and young people should be made aware that they can refuse to participate or stop taking part at any time without explanation (McNaughton and Smith, 2005), which can be enhanced by using participant information sheets that are designed specifically for children, considering the language and study materials design, ensuring they are appropriate and meaningful. This is essential for ensuring participants can make an informed decision about assent, which is key to their developing autonomy in decision-making. If inappropriate, over-complicated language or jargon is used, children may not fully understand what is involved in participating in the research and what, therefore, they are assenting to (Royal College of Nurses, 2011). The material's language and design are also vital during data collection, to ensure the data collected is relevant to and truthfully represents children's sociocultural lives.

\section{Conclusion}

Various approaches to participatory design research with children have emerged from the CCI discipline. Participation levels and their theoretical underpinnings vary. Informant design and CI, whilst potentially empowering activities for children, are founded on child development theories that view children as cognitively immature adults, limiting their participation. The BRIDGE participatory design method is founded on a sociocultural child development view, valuing children's input and viewing them as experts in their daily lives. This results in children being given opportunities to develop social, academic and design skills and to develop autonomy, which can be further enhanced by ensuring children are afforded equal rights as adults when deciding whether to participate in research.

\section{References}

Allsop, M.J., Holt, R.J., Levesley, M.C. and Bhakta, B. (2010), 'The engagement of children with disabilities in health-related technology design processes: identifying methodology', Disability, Rehabilitation and Assistive Technology, Vol. 5 No. 1, pp. $1-13$.

Broome, M.E. (1999), 'Consent (assent) for research with paediatric patients', Seminars in Oncology Nursing, Vol. 15 No. 2, pp. 96 - 103.

Davis, J. (1998), 'Understanding the Meanings of Children: A Reflexive Process', Children and Society, Vol. 12 No. 5, pp. 336-348. 
Druin, A. (2002), 'The Role of Children in the Design of New Technology', Behaviour and Information Technology, Vol. 21 No. 1, pp. 1-25.

European Council Working Group. (2008), Ethical Considerations for clinical trials on medicinal products with the paediatric population, European Parliament and Council of the European Union, Brussels.

Glushko, A. (2013), 'Participatory Design in Healthcare, Patients and doctors can bridge critical information gaps', UX Magazine, article no. 1028, https://uxmag.com/articles/participatory-design-in-healthcare, accessed November 2016.

Goss, J.D., and Leinbach, T.R. (1996), Focus groups as alternative research practice, Area, Vol. 28 No. 2, pp. 115-23.

Guha, M.L. (2010), Understanding the social and cognitive experiences of children involved in technology design processes, Proquest Dissertations and Theses, University of Maryland.

Iversen, O.S. and Brodersen, C. (2007), 'Bridging the Gap between users and children - A socio-cultural approach to designing with children', Cognition, Technology and Work: special issue on Child-Computer Interaction Methodological Research, Vol. 9 No. 2, pp. 83-93.

James, A. and Prout, J. (1997), Constructing and Reconstructing Childhood, Contemporary Issues in the Sociological Study of Childhood, Routledge, London.

Kafai, Y.B., Fields, D.A. and Searle, K.A. (2012), 'Making technology visible: Connecting the learning of crafts, circuitry and coding in youth e-textile designs', Proceedings of the $10^{\text {th }}$ International Conference of the Learning Sciences, pp. 188-195.

Kennedy, C., Kools, S. and Kruger, R. (2001), ‘Methodological considerations in children's focus groups', Nursing Research, Vol. 50 No. 3, pp. 84-87.

Kirk, S. (2007), 'Methodological and Ethical issues in conducting qualitative research with children and young people, A literature review', International Journal of Nursing Studies, Vol. 44 No. 7, pp. 1250-1260.

Kitzinger, J. (1995), 'Introducing focus groups’, British Medical Journal, Vol. 311, pp. 299302.

Lansdown, G. (2009) The realisation of children's participation rights, critical reflections, in Percy-Smith, B. and Thomas, N., editors, 'A Handbook of Children and Young People’s Participation, Perspectives from Theory and Practice', Routledge, London.

Levine, I.S. and Zimmerman, J.D. (1996), 'Using qualitative data to inform public policy, Evaluating Choose to De-Fuse’, American Journal of Orthopsychiatry, Vol. 66 No.3, pp. 363-377.

Light, L., Page, R., Curran, J. and Pitkin L. (2007), 'Children's ideas for the design of AAC assistive technologies for young children with complex communication needs', Augmentative and Alternative Communication, Vol. 23, pp. 274-287.

Lightfoot, J. and Sloper, P. (2002), 'Involving young people in health service development', Research Works, No. 2002-01, pp. 1-4.

Markopoulos, P., Read, J.C., MacFarlane, S.J. and Höysniemi, J. (2008), Evaluating Children's Interactive Products, Morgan Kaufmann, Massachusetts.

Martin, K. and Franklin, A. (2009), Disabled children and participation in the UK, reality or rhetoric? Reflections, in Percy-Smith, B. and Thomas, N., editors, 'A Handbook of Children and Young People's Participation, Perspectives from Theory and Practice', Routledge, London.

McNaughton, G. and Smith, K. (2005) Transforming research ethics: The choices and challenges of researching with children, in Farrell, A., editor, 'Ethical Research with Children', Open University Press, Berkshire. 
Medical Research Council. (2004), MRC Ethics Guide, Medical Research Involving Children, MRC, London.

Morrow, V. and Richards, M.P.M. (1996), 'The ethics of social research with children: an overview', Children \& Society, Vol. 10, pp. 90-105.

Nesset, V. and Large, A. (2004), 'Children in the information technology design process, A review of theories and their applications', Library \& Information Science Research, Vol. 26, pp. 140-161.

Piaget, J. (1972), The psychology of the child, Basic Books, New York.

Race, K.E., Hotch, D.F. and Parker, T. (1994), 'Rehabilitation program evaluation, use of focus groups to empower service users’, Evaluation Review, Vol. 18 No. 6, pp. 73040.

Rigby, P., Ryan, S., From, W., Walczak, E. and Jutai, J. (1996), 'A client-centred approach to developing assistive technology with children', Occupational Therapy International, Vol. 3 No. 11, pp. 67-7.

Royal College of Nurses. (2011), Informed Consent in health and social care research, $2^{\text {nd }}$ edition, RCN, London.

Scaife, M., Rogers, Y., Aldrich, F. and Davies, M. (1997), 'Designing For or Designing With? Informant Design for Interactive Learning Environments', Proceedings of the ACM SIGCHI Conference on Human Factors in Computer Systems, pp. 343-350.

Sims, T. (2014), A Participatory Design Approach to Developing Upper Limb Prostheses for Children and Young People, PhD Thesis, University of Southampton.

Turner, S., Mayall, B. and Mauthner, M. (1995), 'One big rush: Dinner time at school', Health Education Journal, Vol. 54, pp. 18-27.

Uprichard, E. (2008), 'Children as Beings and Becomings: Children, Childhood and Temporality’, Children in Society, Vol. 22, pp. 303-313.

Vosniadou, S. (2001), How Children Learn, International Bureau of Education, Brussels.

Vygotsky, L. (1978), Mind in Society, Harvard University Press, Massachusetts.

Weightman, A.P.H., Preston, N., Holt, R., Allsop, M., Levesley, M. and Bhakta, B. (2010), 'Engaging children in healthcare technology design, developing rehabilitation technology for children with cerebral palsy', Journal of Engineering Design, Vol. 21, No. 5 pp. 579-600.

Whitty, G. and Wisby, E. (2007), Real Decision Making? School Councils in Action, Institute of Education, London.

Wyness, M., Harrison, L. and Buchanan, I. (2004), 'Childhood, Politics and Ambiguity, Toward an Agenda for Children’s Political Inclusion’, Sociology, Vol. 38 No. 1, pp. 81-99.

Table I: Applying the BRIDGE method: Sims' (2014) participatory design of children's upper limb prostheses study.

\begin{tabular}{|l|r|}
\hline BRIDGE method tenets & How it was applied in Sims (2014) \\
\hline $\begin{array}{l}\text { Children assumed as equal stakeholders } \\
\text { in design process. }\end{array}$ & $\begin{array}{l}\text { Children allowed the same } \\
\text { participatory rights as adults through } \\
\text { recognising informed assent as equally } \\
\text { important to informed consent. } \\
\text { - } \\
\text { Assent treated as a changeable state } \\
\text { and not assumed to stand. }\end{array}$ \\
\hline
\end{tabular}




\begin{tabular}{|l|ll|}
\hline $\begin{array}{l}\text { Methods used should be adapted to be } \\
\text { relevant to different cultural stakeholder } \\
\text { groups norms but same methods should } \\
\text { be used to afford equal credence to all } \\
\text { group views. }\end{array}$ & $\begin{array}{l}\text { Age appropriate participant } \\
\text { information and assent form provided. }\end{array}$ \\
& $\begin{array}{l}\text { Similar data collection methods (focus } \\
\text { groups, interviews) used across all }\end{array}$ \\
participant groups. & $\begin{array}{l}\text { Language and activities used in focus } \\
\text { groups were tailored to group } \\
\text { characteristics (using activity } \\
\text { analysis). }\end{array}$ \\
\hline $\begin{array}{l}\text { Children recognised as experts in their } \\
\text { social worlds }\end{array}$ & $\begin{array}{l}\text { Art materials made available for } \\
\text { children to express themselves in ways } \\
\text { other than verbally if desired (but not } \\
\text { imposed). }\end{array}$ \\
\hline $\begin{array}{l}\text { Exploring multiple stakeholder views to } \\
\text { contextualise development }\end{array}$ & $\begin{array}{l}\text { Design began with directly exploring } \\
\text { children's current situation through } \\
\text { discussion with children. }\end{array}$ \\
\hline $\begin{array}{l}\text { Participation encouraged throughout the } \\
\text { design process }\end{array}$ & $\begin{array}{l}\text { Children's views sought first with } \\
\text { other key stakeholder (parents and } \\
\text { professionals) views investigated later } \\
\text { in the design process. }\end{array}$ \\
\hline
\end{tabular}

